\title{
Exposure assessment in the hard metal manufacturing industry with special regard to tungsten and its compounds
}

\author{
T Kraus, P Schramel, K H Schaller, P Zöbelein, A Weber, J Angerer
}

\begin{abstract}
Objectives-To assess the exposure to tungsten, cobalt, and nickel in a plant producing hard metals. The main components of hard metals are tungsten carbide and cobalt metal. According to recent studies, these two components may be responsible for both fibrogenic and carcinogenic effects.
\end{abstract}

Methods-87 workers were investigated (86 male, one female) with a median age of 42 (range 22-58) and a mean duration of exposure of 13 years (range 1-27 years). Stationary and personal air sampling, and biological monitoring were carried out.

Results-Ambient monitoring yielded maximum tungsten concentrations of $417 \mu \mathrm{g} / \mathrm{m}^{3}$ in the production of heavy alloys. A maximum cobalt concentration of $343 \mu \mathrm{g} / \mathrm{m}^{3}$ and a maximum nickel concentration of $30 \mu \mathrm{g} / \mathrm{m}^{3}$ were found at the sintering workshop. The highest urinary cobalt concentrations were found in the powder processing department. The mean concentration was $28.5 \mu \mathrm{g} / \mathrm{g}$ creatinine and the maximum value was $228 \mu \mathrm{g} / \mathrm{g}$ creatinine. The maximum nickel concentration in urine of $6.3 \mu \mathrm{g} / \mathrm{g}$ creatinine was detected in the department producing heavy alloys. The highest tungsten concentrations excreted in urine were found in grinders and had a mean value of $94.4 \mu \mathrm{g} / \mathrm{g}$ creatinine and a maximum of $169 \mu \mathrm{g} / \mathrm{g}$ creatinine. Due to the different solubility and bioavailability of the substance, there was no correlation between the tungsten concentrations in air and urine on a group basis.

Conclusions-Despite its low solubility, tungsten carbide is bioavailable. The different bioavailability of tungsten metal and tungsten compounds has to be considered in the interpretation of ambient and biological monitoring data in the hard metal producing industry. The bioavailability increases in the order: tungsten metal, tungsten carbide, tungstenate. Only if both monitoring strategies are considered in combination can a valid and effective definition of high risk groups be derived.

(Occup Environ Med 2001;58:631-634)

Keywords: tungsten; cobalt; biological monitoring

Correspondence to:

Dr T Kraus

thomas.p.kraus@rzmail.

uni-erlangen.de

Accepted 30 April 2001
Hard metals are widely used in different industries, mainly because of their resistance to corrosion, temperature, and wear. The most important use is as a component of alloys (cemented carbides). These materials were developed decades ago with the sintering process. The main components are tungsten carbide (about 90\%) and cobalt metal (about $10 \%)$. Also, small amounts of nickel may be added. ${ }^{1}$ After occupational exposure to hard metal dust adverse effects on the upper and lower respiratory tract and on the skin have been reported. Although hard metal asthma and effects on the skin are considered to be immunologically mediated reactions, the pathogenic model for interstitial lung disease (hard metal dust fibrosis) is still unclear. ${ }^{2}$ Several studies in the hard metal producing and processing industry suggested that cobalt is the main aetiological agent for the development of interstitial fibrosis. As a consequence of these studies preventive measures were initiated to reduce exposure to cobalt. ${ }^{3-5}$ These measures were very successful, especially the use of a metal working fluid containing a complex binder which generated a cobalt complex that reduced the bioavailability of cobalt. According to the results of biological monitoring, this measure has led especially in hard metal grinders to a significant reduction in exposure to cobalt. ${ }^{6}$

Several in vitro and animal experiments carried out over the past few years suggest that tungsten carbide also plays an important part in the pathogenesis of hard metal dust fibrosis as a result of a synergistic effect. In vitro experiments have shown that the toxicity of hard metal dusts is determined by the physicochemical interaction of cobalt and tungsten carbide. Animal experiments have shown that the incidence of fibrotic lung changes is higher when a mixture of cobalt and tungsten carbide is administered, whereas cobalt and tungsten carbide alone lead to only low fibrogenic activity. ${ }^{2} 8$

In the United States and in some European countries the ambient threshold limit values are in the range of $1 \mathrm{mg} / \mathrm{m}^{3}$ for soluble tungsten compounds and $5 \mathrm{mg} / \mathrm{m}^{3}$ for insoluble ones. The aim of these limits is to prevent effects on the central nervous system occurring after exposure to soluble compounds and irritative effects on the respiratory tract with insoluble compounds. In Germany a maximum concentration at the workplace (MAK) value of $1 \mathrm{mg} / \mathrm{m}^{3}$ for soluble tungsten compounds and $5 \mathrm{mg} / \mathrm{m}^{3}$ for insoluble compounds has been set. ${ }^{9}$ To date there are no biological exposure indices for internal exposure to tungsten. For 
cobalt compounds the technical exposure limit (TRK) value in Germany is $0.5 \mathrm{mg} / \mathrm{m}^{3}$ for cobalt in the form of cobalt metal, cobalt oxide, and cobalt sulfide in the production of cobalt powder, hard metals, machine pressing, and mechanical processing of unsintered articles and $0.1 \mathrm{mg} / \mathrm{m}^{3}$ in other fields of production and processing. ${ }^{10}$ The exposure equivalents for carcinogenic materials (EKA) values are $30 \mu \mathrm{g} / 1$ urinary cobalt for $0.05 \mathrm{mg} / \mathrm{m}^{3}$ cobalt in air, 60 $\mu \mathrm{g} / \mathrm{l}$ urinary cobalt for $0.10 \mathrm{mg} / \mathrm{m}^{3}$ cobalt in air and $300 \mu \mathrm{g} / 1$ urinary cobalt for $0.50 \mu \mathrm{mg} / \mathrm{m}^{3}$ cobalt in air. ${ }^{10}$ The reference value for urinary cobalt is $1.5 \mu \mathrm{g} / \mathrm{l}$. The TRK value for nickel as metallic nickel, nickel sulfide, and sulfide containing ores, nickel oxide, and nickel carbonate is $0.5 \mathrm{mg} / \mathrm{m}^{3}$. The EKA values are $15 \mu \mathrm{g} / \mathrm{l}$ urinary nickel for $0.10 \mathrm{mg} / \mathrm{m}^{3}$ nickel in air, $30 \mu \mathrm{g} / 1$ urinary nickel for $0.30 \mathrm{mg} / \mathrm{m}^{3}$ nickel in air and $45 \mu \mathrm{g} / 1$ urinary nickel for $0.50 \mathrm{mg} / \mathrm{m}^{3}$ nickel in air. $^{10}$ The reference value for urinary nickel is $2.2 \mu \mathrm{g} / 1$.

In the hard metal producing industry an increase in the incidence of lung cancer has been found. ${ }^{11-14}$ Therefore the International Agency for Research on Cancer (IARC) has suggested categorising cobalt and cobalt compounds as possibly carcinogenic to humans. ${ }^{15}$ Exposure to tungsten carbide, however, was not considered in earlier studies. To be able to evaluate the risk of cancer in the hard metal industry, the exposure situation needs to be assessed not only for cobalt and its compounds but also for tungsten and nickel. To our knowledge there are no data available on exposure to cobalt, nickel, and especially tungsten in the hard metal producing industry.

The aim of this study was therefore to assess the external and internal exposure of workers exposed to hard metal dust to define high risk groups in which synergistic effects may occur and for whom specific screening activities could be initiated.

\section{Study group and methods}

We investigated 87 workers ( 86 male, one female) with a median age of 42 (range 22-58) from different workshops in a hard metal producing plant. All workers were included in the study. In the different workshops processing of the powder (mixture), the production of heavy alloys, pressing, forming, sintering, grinding, and maintenance were carried out. The median exposure period was 13 (range 1-27) years. Informed written consent was obtained

Table 1 Results of ambient monitoring of cobalt, nickel and tungsten in different workshops

\begin{tabular}{llllll}
\hline & & & $\begin{array}{l}\text { Cobalt } \\
\left(\mu g / m^{3}\right)\end{array}$ & $\begin{array}{l}\text { Tungsten } \\
\left(\mu g / m^{3}\right)\end{array}$ & $\begin{array}{l}\text { Nickel } \\
\left(\mu g / m^{3}\right)\end{array}$ \\
\hline Forming & $\mathrm{P}$ & 5 & $0.61-2.82$ & $7.8-97.4$ & $0.23-0.76$ \\
Pressing & $\mathrm{S}$ & 1 & 1.32 & 6.2 & 0.30 \\
Powder processing & $\mathrm{P}$ & 3 & $0.87-116.0$ & $5.3-211.0$ & $0.32-3.0$ \\
Production of tungsten carbide & $\mathrm{P}$ & 4 & $7.9-64.3$ & $177.0-254.0$ & $0.76-1.65$ \\
Sintering & $\mathrm{P}$ & 1 & 0.39 & 19.1 & 0.40 \\
Grinding (wet) & $\mathrm{P}$ & 1 & 343.0 & 12.1 & 29.6 \\
Grinding (dry) & $\mathrm{S}$ & 1 & 1.3 & 5.9 & 0.07 \\
Heavy alloy production & $\mathrm{P}$ & 1 & 0.20 & 3.3 & 0.13 \\
& $\mathrm{P}$ & 1 & 0.48 & 81.3 & 0.31 \\
& $\mathrm{P}$ & 2 & $0.85-1.84$ & $125.0-417.0$ & $0.48-2.17$ \\
& $\mathrm{~S}$ & 3 & $0.63-8.50$ & $50.0-163.0$ & $0.72-1.70$
\end{tabular}

$\mathrm{P}=$ personal sampling; $\mathrm{S}=$ stationary sampling. from each participant. The protocol was approved by the ethics committee of the Medical School of the Friedrich-Alexander University Erlangen-Nuremberg, Germany.

The study design included a standardised questionnaire with special interest in symptoms and diseases of the respiratory tract. Assessment of the exposure situation took into account former occupational exposure and current exposure. Also stationary and personal air sampling were performed in every workshop with at least one worker in each workshop.

Stationary air monitoring was performed with a VC 25 (air flow rate $22.5 \mathrm{~m}^{3} / \mathrm{h}$, nitrocellulose acetate filters, pore size $8 \mu \mathrm{m}, 150 \mathrm{~mm}$ diameter). The respirable dust fraction was measured. Personal air monitoring was performed with a DuPont P4000 sampling device (air flow rate $210 \mathrm{l} / \mathrm{h}$, nitrocellulose acetate filters, pore size $0.8 \mu \mathrm{m}, 37 \mathrm{~mm}$ diameter) with Casella cyclons for respirable dust fraction. The mean sampling time was 4 hours (range 1 hour to 5 hours 42 minutes). After wet oxidative digestion $\left(\mathrm{HCl} / \mathrm{HNO}_{3} 4: 1\right)$ of the filters, measurements were performed with graphite furnace atomic absorption spectrometry (cobalt and nickel) and inductively coupled plasma spectroscopy (tungsten, details later).

Urinary cobalt, tungsten, and nickel was measured in all workers. The samples were taken at the end of the shift after 4 consecutive working days on the same day that air sampling was done. Special precautions were taken to avoid contamination of the urine samples. The measurement of urinary cobalt and nickel was performed according to the recommendations of the Working Group on Analyses of Hazardous Substances in Biological Materials of the DFG by graphite furnace atomic absorption spectrometry. ${ }^{16}$ The analytical detection limit for urinary cobalt is $0.1 \mu \mathrm{g} / 1$, for urinary nickel $0.2 \mu \mathrm{g} / \mathrm{l}$. The tungsten analysis was carried out by inductively coupled plasma spectroscopy with low resolution mass spectrometry after ultraviolet digestion. Tungsten $\left({ }^{184} \mathrm{~W}\right)$ was assessed by mass spectrometry with iridium $\left({ }^{193} \mathrm{Ir}\right)$ as an internal standard. Calibration was performed with aqueous tungsten standard solutions. The detection limit in urine was 0.05 $\mu \mathrm{g} / \mathrm{l}$. Because of the lack of reference values for samples of tungsten in urine from the general population, we analysed urine samples from 33 people not occupationally exposed to tungsten.

\section{Results}

Ambient monitoring yielded maximum tungsten concentrations of $417 \mu \mathrm{g} / \mathrm{m}^{3}$ in the production of heavy alloys. A maximum cobalt concentration of $343 \mu \mathrm{g} / \mathrm{m}^{3}$ and a maximum nickel concentration of $30 \mu \mathrm{g} / \mathrm{m}^{3}$ were found at the sintering workshop (table 1). The maximum concentrations at the workplace for tungsten and the German technical exposure limits for cobalt and nickel were not exceeded. The results of ambient monitoring show that the concentrations of exposure at the different workshops vary greatly.

The results of biological monitoring for the different workshops are presented in table 2 . 
Table 2 Results of biological monitoring for urinary cobalt, nickel, and tungsten in different workshops

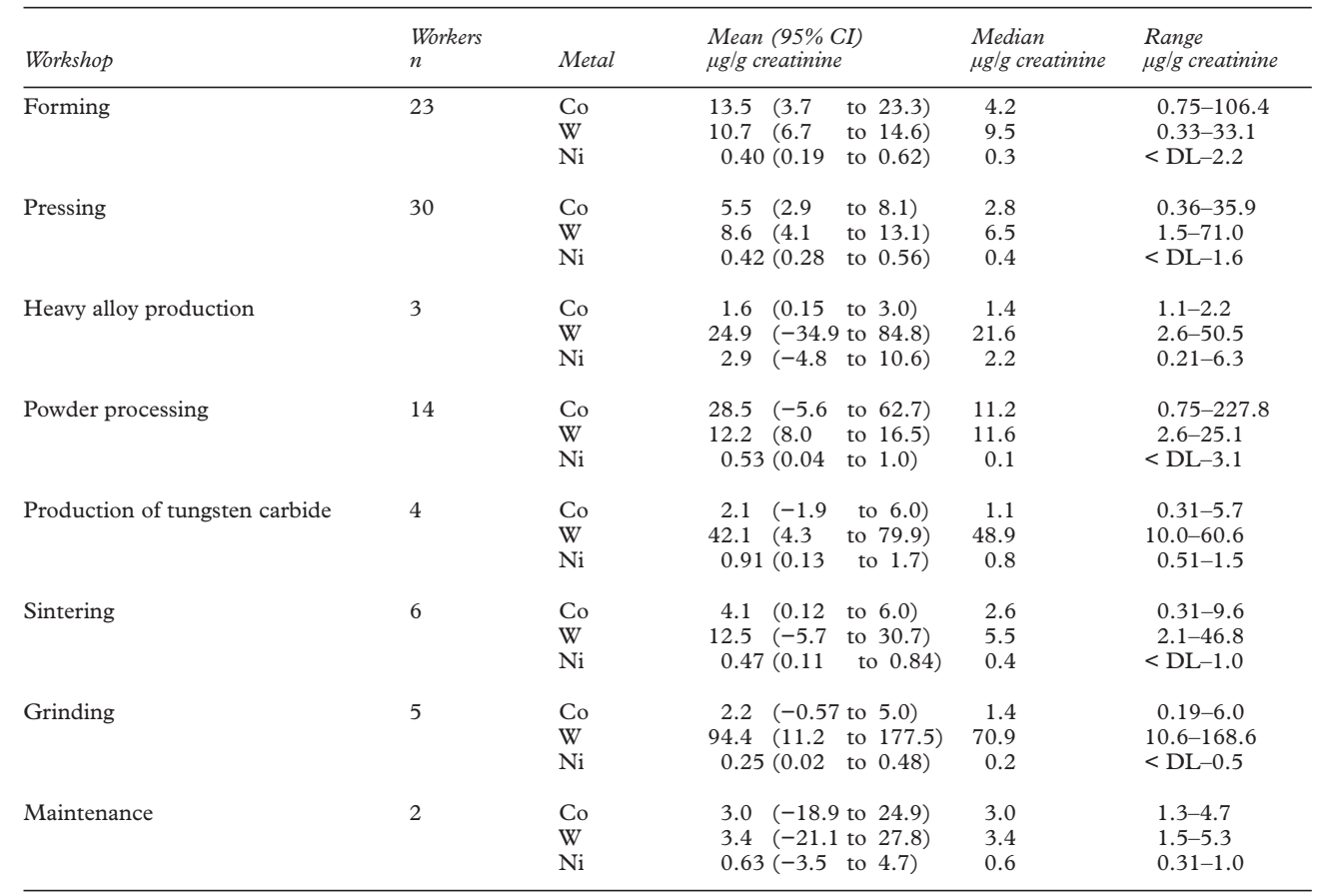

$\mathrm{Co}=$ cobalt; $\mathrm{W}=$ tungsten; $\mathrm{Ni}=$ nickel; $\mathrm{DL}=$ detection limit.

The highest cobalt concentrations were found in the powder processing department with a mean concentration of $28.5 \mu \mathrm{g} / \mathrm{g}$ creatinine and a maximum value of $228 \mu \mathrm{g} / \mathrm{g}$ creatinine. Concentrations above the exposure equivalent for carcinogenic substances of $60 \mu \mathrm{g} / 1$ urine were found in the departments where forming $(n=1)$ and powder processing $(n=2)$ were carried out.

The nickel concentrations at the workplace and in the urine samples of the workers were very low. The maximum nickel concentration in urine of $6.26 \mu \mathrm{g} / \mathrm{g}$ creatinine was found in the department producing heavy alloys. Nickel concentrations above the exposure equivalent for carcinogenic substances (EKA) of $45 \mu \mathrm{g} / 1$ could not be detected.

The mean tungsten concentrations in urine of non-exposed people were $0.31 \mu \mathrm{g} / 1$ (range $<$ detection limit (DL)-0.87) and $0.30 \mu \mathrm{g} / \mathrm{g}$ creatinine (range $<\mathrm{DL}-1.22$ ). The reference values (95th percentile) were $0.86 \mu \mathrm{g} / 1$ and $1.00 \mu \mathrm{g} / \mathrm{g}$ creatinine. The tungsten concentrations in urine of the exposed workers varied greatly between the different workshops (table 2 ). The highest tungsten concentrations excreted in urine were found in grinders who had a mean value of $94.4 \mu \mathrm{g} / \mathrm{g}$ creatinine and a maximum value of $169 \mu \mathrm{g} / \mathrm{g}$ creatinine. High tungsten concentrations were also detected in the departments producing tungsten carbide (42.1 $\mu \mathrm{g} / \mathrm{g}$ creatinine) and heavy alloys (24.9

Table 3 Ambient and biological monitoring of different tungsten species

\begin{tabular}{lllll}
\hline & $n$ & $\begin{array}{l}\text { Tungsten } \\
\text { species }\end{array}$ & $\begin{array}{l}\text { Tungsten in air } \\
\left(\mu g / m^{3}\right) \\
\text { mean (range) }\end{array}$ & $\begin{array}{l}\text { Tungsten in urine } \\
(\mu g / g \text { creatinine) } \\
\text { mean (range) }\end{array}$ \\
\hline Powder processing & 4 & W & $203.5(177.0-254.0)$ & $13.8(2.6-21.1)$ \\
Forming, pressing, sintering & 8 & WC & $53.5(5.3-211.0)$ & $9.5(2.2-33.1)$ \\
Production WC & 1 & WC, WO, W & 19.1 & 59.6 \\
Grinding (wet) & 1 & WO $_{4}{ }^{2-}$ & 3.3 & 70.9 \\
Grinding (dry) & 1 & WO, WC & 81.3 & 10.6 \\
\hline
\end{tabular}

$\mathrm{WO}=$ tungsten oxide, $\mathrm{WO}_{4}{ }^{2-}=$ tungstenate, $\mathrm{W}=$ tungsten metal, $\mathrm{WC}=$ tungsten carbide. $\mu \mathrm{g} / \mathrm{g}$ creatinine). Duration of exposure had no effect on the urinary concentrations of cobalt, nickel, and tungsten.

In the different workshops the species of the metal compounds vary. This must be considered when interpreting the results. There is exposure to tungsten carbide in the forming, pressing, and sintering workshops. Exposure to a combination of tungsten carbide, tungsten oxide, and tungsten metal occurs in the tungsten carbide production workshop. Exposure to tungsten metal alone is found in the powder processing department. Grinders are exposed to tungstenate when wet grinding is carried out and to tungsten oxide and carbide when dry grinding is carried out. These differences must be considered because of the different bioavailability of the various metal species. A correlation between the results of ambient monitoring and biological monitoring on a group basis is therefore not expected. Table 3 shows ambient and biological monitoring results for different tungsten compounds used in the workshops. The correlations found reflect the different bioavailability of the tungsten species at different workplaces. With exposure to tungsten metal, relatively high concentrations were found in air compared with relatively low tungsten concentrations in urine. The concentrations of tungsten carbide in air and urine cover a wide range. The table shows that tungsten carbide, despite its relatively low solubility, is bioavailable to a considerable degree. Combined exposure to tungsten metal and tungsten carbide is of greater bioavailability than tungsten carbide alone with comparable concentrations in air. The highest bioavailability was detected for tungstenate, with increased urinary concentrations corresponding to low concentrations of tungsten in air. 


\section{Discussion}

In view of the numerous cases of interstitial lung disease among hard metal workers and the suspected carcinogenicity of hard metal dusts, it is important that in future the exposure situation at the different workplaces be validly assessed. This is the prerequisite for the detection of dose-response relations in workers from the hard metal industry. In this study exposure to tungsten was assessed for the first time as well as the hard metal components cobalt and nickel.

The tungsten concentrations in air and in urine were analysed by inductively coupled plasma spectroscopy with low resolution mass spectrometry, which proved to be a valid method for the assessment of tungsten exposure. ${ }^{17}{ }^{18}$ With this technique it is possible to differentiate between the renal excretion of tungsten in occupationally exposed and nonexposed people. Exposed people were found to excrete significantly higher concentrations of tungsten in urine than people not exposed. The 95th percentile for the general population is 1 $\mu \mathrm{g} / \mathrm{g}$ creatinine.

During the hard metal manufacturing process various tungsten compounds and tungsten metal are used in the different workshops. The tungsten species have different degrees of bioavailability. This means that a correlation between internal and external tungsten exposure on a group basis cannot be expected. The bioavailability increases in the order: tungsten metal, tungsten carbide, tungstenate. The maximum tungsten concentrations in urine were therefore found in wet grinders, as tungstenate enriches in the metal working fluid. At these workplaces very low tungsten concentrations in air of $3.3 \mu \mathrm{g} / \mathrm{m}^{3}$ were found. Despite its low solubility, tungsten carbide is bioavailable to a considerable degree. The results show that ambient monitoring alone and biological monitoring alone are not representative for the assessment of the exposure of hard metal workers. Ambient monitoring alone provides no information about the bioavailable fraction of the exposure. Biological monitoring alone gives only incomplete information about the exposure of the target organ, the lung. Regulations based on ambient or biological monitoring alone are therefore incomplete and involve errors. This might lead to inappropriate preventive measures. Therefore a combination of both methods of monitoring is recommended for the definition of groups at risk necessary for effective and efficient prevention of disease. The methods used in this study allow the valid identification of exposure to tungsten and of exposure to cobalt and nickel in the hard metal manufacturing industry.

The results of this study show that exposure to cobalt, which was thought to be the main pathogenic factor in the development of hard metal dust fibrosis, has been reduced compared with the concentrations found in earlier studies. This has been achieved by use of metal working fluids with complex binding additives. ${ }^{19}$ High levels of exposure to cobalt could only be found in individual cases, especially in the powder processing department. Exposure to nickel does not seem to play an important part in this industry. Increased concentrations could be found in neither air nor urine.

\section{Conclusion}

The different bioavailability of tungsten metal and tungsten compounds must be considered in the interpretation of data from ambient monitoring and biological monitoring in the hard metal producing industry. The bioavailability increases in the order: tungsten metal, tungsten carbide, tungstenate. Only if these results are considered in combination, can a valid and effective definition of high risk groups be derived. High risk groups should be the main focus of preventive measures and further studies on the risk of lung cancer and interstitial lung disease should be carried out

1 Lison D. Human toxicity of cobalt-containing dust and experimental studies on the mechanism of interstitial lung diesease (hard metal disease). Crit Rev Toxicol 1996;26:585-616.

2 Lison D, Lauwerys R, Demedts M, et al. Experimental research into the pathogenesis of cobalt/hard metal lung disease. Eur Respir F 1996;9:1024-8.

3 Sjögren I, Hillerdal G, Andersson A, et al. Hard metal lung disease: importance of cobalt in coolants. Thorax 1980;35: 653-9.

4 Hartung M. Lungenfibrosen bei Hartmetallschleifern. Forschungsbericht Cobalteinwirkung. Schriftenreihe des Hauptverbandes der gewerblichen Berufsgenossenschaften: Bonn: tverbandes der gewerblichen Berufsgenossen

Köllen Druck and Verlag GmbH, 1986 .
5 Hartung M, Schaller KH. Arbeitsmedizinische Bedeutung der Cobalt-Exposition bei Hartmetallschleifern. In: Norpoth K, ed. Bericht über die 27. Fahrestagung der Deutschen Gesellschaft für Arbeitsmedizin e.V. Stuttgart: Gentner Verlag, 1987:55-62.

6 Hartung M. Ätiologie, Pathogenese und Klinik der Hartmetallfibrose der Lunge. Pneumologie 1990;44:49-54.

7 Anard D, Kirsch-Volders M, Elhajouji A, et al. In vitro genotoxic effects of hard metal particles assessed by alkaline single cell gel and elution assay. Carcinogenesis 1997;18:177-84

8 Van Goethem F, Lison D, Kirsch-Volders M. Comparative evaluation of the in vitro micronucleus test and the alkaline single cell gel electrophoresis assay for the detection of DNA damaging agents: genotoxic effects of cobalt powder, tungsten carbide and cobalt-tungsten carbide. Mutat Res 1997;392:31-43.

9 TRGS 900 (Technical guidance note for hazardous substances). Tungsten and tungsten compounds. Bundesubstances). Tungsten and
sarbeitsblatt 2000;10:34-70

10 Commission for the Investigation of Health Hazards of Chemical Compounds in the Work Area. DFG, ed. List of $M A K$ and BAT values 2000. Weinheim: VCH-Wiley, 2000. (Report No 36.)

1 Hogstedt C, Alexandersson R. Mortality among hard metal workers. Arbete Hälsa 1990;21:1-26.

2 Lasfargues G, Wild P, Moulin JJ, et al. Lung cancer mortality in a French cohort of hard-metal workers. $A m \mathcal{F}$ Ind Med 1994;26:585-95.

13 Moulin JJ, Wild P, Romazini S, et al. Lung cancer risk in hard-metal workers. Am f Epidemiol 1998;148:241-8.

14 Wild P, Perdrix A, Romazini S, et al. Lung cancer mortality in a site producing hard metals. Occup Environ Med
$2000 ; 57: 568-73$.

15 Cobalt and cobalt compounds. IARC Monographs on the evaluation of carcinogenic risks to humans. Volume 52 : Lyon, France: IARC, 1991

16 Angerer J, Schaller KH, eds. Analyses of hazardous substances in biological materials. Vol 1-6. Weinheim: Wiley VCH, 1999.

17 Angerer J, Hartung M, Schramel P, et al. Wolfram- und Cobalt-Exposition an Arbeitsplätzen der Hartmetallherstellung. In: Schuckmann F, Schopper-Jochum S, eds. Bericht über die 30. Fahrestagung der Deutschen Gesellschaft für Arbeitsmedizin e. V. Stuttgart: Gentner Verlag, 1990:305-08.

18 Schramel P, Wendler I, Angerer J. The determination of metals (antimony, bismuth, lead, cadmium, mercury, palladium, platinum, tellurium, thallium, tin and tungsten) in urine samples by inductively coupled plasma-mass spectrometry. Int Arch Occup Environ Health 1997;69:219-23.

19 Hartung M, Schaller KH, Valentin H. Prophylaxe von Lungenfibrosen bei Hartmetallschleifern durch Anwendug eines neuen Kühlschmiermittels? In: Norpoth K, ed. eines neuen Kühlschmiermittels? In: Norpoth K, ed. Bericht über die 27. Fahrestagung der Deutschen Gesellschaft für 1987:331-3. 